\title{
Article
}

\section{Analysis of Medical Services for Insomnia in Korea: A Retrospective, Cross-Sectional Study Using the Health Insurance Review and Assessment Claims Data}

\author{
Chaewon Son ${ }^{1}$, Yu-Cheol Lim ${ }^{2}$, Ye-Seul Lee ${ }^{2}$ D, Jung-Hwa Lim ${ }^{3,4}$, Bo-Kyung Kim ${ }^{3,4, *,+}$ and In-Hyuk Ha ${ }^{2, *},+(\mathbb{D}$ \\ 1 Jaseng Hospital of Korean Medicine, 536 Gangnam-daero, Gangnam-gu, Seoul 06110, Korea; \\ sohn.sppcf@gmail.com \\ 2 Jaseng Spine and Joint Research Institute, Jaseng Medical Foundation, 3F, 538 Gangnam-daero, Gangnam-gu, \\ Seoul 06110, Korea; hmh6692@gmail.com (Y.-C.L.); yeseul.j.lee@gmail.com (Y.-S.L.) \\ 3 Department of Neuropsychiatry, School of Korean Medicine, Pusan National University, Gumo-ro 20, \\ Mulgeum-eup, Yangsan 50612, Korea; suede22@hanmail.net \\ 4 Department of Neuropsychiatry, Pusan National University Korean Medicine Hospital, Gumo-ro 20, \\ Mulgeum-eup, Yangsan 50612, Korea \\ * Correspondence: npjolie@hanmail.net (B.-K.K.); hanihata@gmail.com (I.-H.H.); \\ Tel.: +82-55-360-5965 (B.-K.K.); +82-2-2222-2740 (I.-H.H.) \\ + Both authors contributed equally as co-corresponding authors.
}

check for updates

Citation: Son, C.; Lim, Y.-C.; Lee, Y.-S.; Lim, J.-H.; Kim, B.-K.; Ha, I.-H. Analysis of Medical Services for Insomnia in Korea: A Retrospective, Cross-Sectional Study Using the Health Insurance Review and Assessment Claims Data. Healthcare 2022, 10, 7. https://doi.org/10.3390/ healthcare10010007

Academic Editor: Victor Kallen

Received: 18 November 2021

Accepted: 17 December 2021

Published: 22 December 2021

Publisher's Note: MDPI stays neutral with regard to jurisdictional claims in published maps and institutional affiliations.

Copyright: (C) 2021 by the authors. Licensee MDPI, Basel, Switzerland. This article is an open access article distributed under the terms and conditions of the Creative Commons Attribution (CC BY) license (https:// creativecommons.org/licenses/by/ $4.0 /)$.

\begin{abstract}
This study aimed to analyze current trends in healthcare utilization and medication usage in patients with insomnia. We reviewed the National Patient Sample data from the Health Insurance Review and Assessment Service to determine healthcare utilization in patients diagnosed with insomnia (International Classification of Diseases-10 codes G470, F510) between January 2010 and December 2016. There were 87,470 patients enrolled in this study who utilized healthcare services at least once during the 7-year period. Healthcare utilization trends, Korean and Western medicine (KM and WM, respectively) therapies utilized, comorbidities, and socioeconomic data were analyzed. The number of patients seeking WM or KM care for insomnia increased annually. Adults aged $\geq 45$ years accounted for $73 \%$ of the cohort, and there were more female than male patients. KM treatment including acupuncture was the most common in KM (65.29\%), while examination was the most common WM treatments (49.31\%). In pharmacological therapy, sedatives and hypnotics were the most common $(41.08 \%)$, followed by antianxiety $(19.50 \%)$, digestive system and metabolism-related drugs $(7.77 \%)$. The most common comorbidities were mental health disorders $(50.56 \%)$ in WM but musculoskeletal disorders in KM (35.67\%). Code G470 was used more frequently than code F510, and the difference was more evident in KM than in WM. The findings will provide valuable information for both clinicians and researchers.
\end{abstract}

Keywords: insomnia; medical service utilization; cost of care; hypnotics; sedatives

\section{Introduction}

Insomnia is defined as the persistence of symptoms such as difficulty initiating or maintaining sleep or early-morning waking at least three times a week for $\geq 3$ months [1]. Insomnia is a very common disorder, and intermittent short-term insomnia affects approximately $30-50 \%$ of the total population. A study in the United States (US) and United Kingdom (UK) reported an acute insomnia prevalence of $9.5 \%$ and $7.9 \%$, respectively, with an annual incidence of 31.2-36.6\% [2]. A study in Korea reported that one in five adults develops insomnia [3]. The prevalence of insomnia also increases with age; approximately $50 \%$ of older adults have difficulty initiating or maintaining sleep [4]. Further, the prevalence of insomnia according to the International Classification of Sleep Disorders-2 (ICSD-2) criteria was $32.7 \%$ among Korean older adults [5].

Insomnia is multifactorial [6]. Smoking, alcohol use, and diminished physical activity are associated with insomnia in older adults. The risk factors for insomnia include being 
divorced, separated, or widowed (for women); having a low education level; and having a low income level [7]. Insomnia may cause severe pain and injury in the body, as well as fatigue, daytime sleepiness, cognitive impairment, and mood disorders [6]. Sleep deprivation can result in deterioration of the overall quality of life, characterized by depression and poor work performance, and chronic insomnia can increase mortality by activating the inflammatory processes in the body and inducing cardiovascular diseases [8,9].

The goal of insomnia treatment is to improve sleep and reduce any resultant suffering or functional impairments [10]. Cognitive behavioral therapy for insomnia (CBT-I) is suggested as the first-line treatment for adult chronic insomnia by the American College of Physicians clinical practice guidelines (2016), European Sleep Research Society clinical practice guidelines (2017), and American Academy of Sleep Medicine guidelines for the assessment and treatment of adult chronic insomnia (2008) [10-12]. In general, CBT-I comprises: (1) education regarding normal sleep, sleep hygiene, and the purpose of CBTI-I, (2) stimulus control therapy, (3) sleep restriction therapy, (4) relaxation techniques, and (5) cognitive therapy [13]. If CBT-I alone is inadequate or ineffective, pharmacological therapy can be considered. Appropriate doses of drugs for treating adult sleep initiation and sleep maintenance difficulties are used separately, and pharmacological therapy beyond four weeks is not recommended. Drugs used in Korea for sleep initiation include zolpidem, triazolam, and ramelteon; those used for sleep maintenance or early morning awakenings include eszopiclone, doxepin, trazodone, suvorexant, and zolpidem controlled-release (CR) [14].

The degree of symptom improvement achieved with insomnia treatment differs among patients. Previous studies report an insomnia persistence rate of $40-69 \%$ over a period of 1-20 years [15], suggesting that chronic insomnia can be a substantial financial burden on society [16]. According to a World Health Organization report, insomnia is ranked eleventh on the list of mental, neurological and substance-use disorders with the greatest disease burden worldwide [17]. A 2010 European study comparing the direct and indirect costs of various brain diseases ranked insomnia as the ninth among neuropsychiatric disorders [18]. Although specific estimates can vary widely depending on the methodology, insomnia-related direct and indirect cost estimates in the US are reported to be $2-16$ billion USD and 75-100 billion USD, respectively [16]. The indirect costs were mostly incurred by worker absenteeism, presenteeism (diminished daytime productivity), and occupational accidents [19]. A Korean epidemiology study on sleep disorders reported that $22.8 \%$ of 5000 adults had insomnia [20], and a Health Insurance Review and Assessment Service (HIRA) report showed that the number of patients being treated for insomnia increased from 405,000 in 2015 to 633,000 in 2019, with the total amount of covered health benefits increasing from 38.7 billion KRW in 2012 to 66.7 billion KRW in 2016 [21].

The escalating prevalence of insomnia, and consequent direct and indirect costs of care, demand an examination of the latest trends in insomnia care. As previously mentioned, Western clinical practice guidelines recommend CBT-I followed by pharmacological therapy to treat insomnia. However, there are limitations in the clinical implementation of CBT-I, and medication compliance is low among patients because of concerns regarding developing tolerance and dependence and adverse drug reactions with prolonged use, such as disturbance of sleep flow [22]. As a result, alternative therapy is sometimes used to treat insomnia; popular alternatives include phototherapy, exercise therapy, and acupuncture therapy $[10,23,24]$. Research on such alternative therapies is ongoing. One study investigating the short-term effects of acupuncture on sleep quality reported that acupuncture improved sleep efficiency and total sleep duration compared with placebo treatment [25]. Acupuncture therapy is less costly compared with psychotherapies, is not time consuming, and can be adjusted depending on the targeted symptom [26].

South Korea features a bimodal healthcare system, wherein patients with insomnia have the option to receive covered care at Western medicine (WM) or Korean medicine (KM) facilities. KM treatments include acupuncture, moxibustion, cupping therapy, herbal medicine, and KM psychotherapy. Korean patients can receive WM and KM treatments concomitantly; therefore, there may be differences in the limitations of these treatments and 
their socioeconomic burden in Korea compared with that from other countries, which highlights the need for studies that consider both KM and WM treatments. Previous studies primarily examined the treatment trends in WM, with a focus on analyzing the relationship between insomnia and a single factor such as sex, age, and type of pharmacological therapy $[5,27,28]$.

This study aimed to investigate the characteristics of insomnia patients, available WM and KM services, utilization of these services, medical costs, and comorbidities and analyze their trends using the 2010 to 2016 Health Insurance Review and Assessment (HIRA) claims data. The HIRA-National Patient Sample (NPS) data are nationally representative data that enable a comparison of WM and KM utilization by patients with insomnia. We ultimately aimed to present reliable foundational data for clinicians, researchers, and policymakers to contribute to effective healthcare policies.

\section{Materials and Methods}

\subsection{Data Source}

We used the HIRA-NPS data from January 2010 to December 2016, employing data in which the neuropsychological disease codes remained unmasked. The HIRA data are insurance claims data generated when healthcare providers submit their claims for reimbursement of costs of healthcare provided to patients. Because $>98 \%$ of the Korean population is covered by national health insurance, these data are nationally representative and, thus, highly valuable for healthcare research [29]. These data provide detailed information on various factors: details of care (e.g., treatment, procedure, test, drug prescriptions), diagnosis, cost covered by the insurer, patient's out-of-pocket cost, patient's demographic information, and information on the healthcare facility.

The HIRA-NPS includes claims data of randomly selected patients (3\%; approximately $1,375,842$ as of 2011) from the total population and is stratified by sex (two strata) and age (16 strata). Since only a small percentage of the patients are included every year, the dataset is analyzed under the assumption that there is a very low possibility of overlapping patients. These are secondary data sampled from the raw data after removing information regarding individuals and legal entities; the data contain annual claims with reference to the first day of care of the corresponding year.

\subsection{Study Design and Study Population}

The International Classification of Diseases-Tenth Revision (ICD-10) codes used for diagnosing insomnia are F codes (psychiatrics) and G codes (neurology), and the frequently used codes include F510 (nonorganic insomnia), F518 (other nonorganic sleep disorders), F519 (nonorganic sleep disorder, unspecified), F519A (emotional sleep disorder NOS), G470 (disorders of initiating and maintaining sleep, insomnias), G470A (chronic insomnia), G470B (acute insomnia), G472 (disorders of the sleep-wake schedule), G472C (irregular sleep-wake patterns), G478 (other sleep disorders), and G479 (sleep disorder, unspecified). In this study, only patients who received WM or KM care at least once with the code F510 (nonorganic insomnia) or G470 (disorders of initiating and maintaining sleep, insomnias) as the main diagnosis between 2010 and 2016 were included. These criteria were adopted from a previous Korean study [28].

Among the claims submitted with Korean Standard Classification of Diseases (KCD) codes F510 or G470, cases with a code for dentistry or public health facility (6167 cases); cases with the type of institution listed as a dental hospital, maternity clinic, or public health facility (225 cases); cases of patients diagnosed with a cancer-related code during the observation period $(76,262$ cases); or cases with the total cost and number of days in care entered as 0 or missing (1448 cases) were excluded.

\subsection{Study Outcomes}

General medical service use of insomnia patients according to the type of visit was investigated by each year. The patients whose data were selected for the analysis were classified based on baseline characteristics such as age, sex, payer type, type of visit, and 
medical institution, and the frequency and percentage of each parameter. Age was divided into eight categories of 10 -yearly units from $<15$ years to $\geq 75$ years; payer type was divided into health insurance, Medicaid, and others. The type of visit was classified into outpatient care and inpatient care based on the claim, and medical institution was divided into tertiary hospital/general hospital/hospital, clinic, KM hospital, and KM clinic.

The service category in the HIRA-NPS database was divided into examination fee, injection fee, KM treatment, psychotherapy fee, hospitalization, radiological diagnosis, test, treatment/surgery, and others, and the frequency and total expense for each category were analyzed. We analyzed cases of acupuncture (acupoint, special acupoint, zone, and device), a treatment in which needles are injected into acupoints based on KM pattern identification, and these cases were specified as KM treatment. Total expense was defined as the sum of the expenses of care paid by the patient's out-of-pocket costs and insurer, which is covered by the National Health Insurance Service.

The service codes for insomnia-related treatment were divided into WM and KM for analysis. The number of services, total expenses, number of patients, average annual expense per service, and average annual expenses per patient were analyzed for psychotherapies in WM and for acupuncture, moxibustion, cupping therapy, and psychotherapies in KM. Psychotherapies in KM were categorized into four different therapies (a. Gyeongja-pyeongji therapy, b. Oji-sangseung therapy, c. Ijeong-byeongi therapy, and d. Jieon-goron therapy) [30,31]. The main characteristic of the psychotherapy in KM is its theoretical basis, more specifically theories in Korean Medicine in understanding emotions and psychological disorders, which can be explained in two parts: one is that emotions and psychological states are interrelated, which allows moderation or enhancement of one emotion by another; two is that emotions can be resolved by not only conversations and interactions but also by external stimuli such as physical stimulations [32].

We categorized the inpatient and outpatient drug prescriptions according to the anatomical therapeutic chemical classification codes with reference to the Ministry of Health and Welfare classification criteria and analyzed the frequency and expenses for each category. Prepared herbal medicine was excluded as it is not covered by health insurance. Comorbidities of insomnia were analyzed separately for WM and KM for all main and sub-diagnosis codes, including F510 and G470. Among the codes for insomnia, codes equivalent to ICD codes F510 and G470 were analyzed separately for WM and KM to compute the total number and percentage of claims with each of these codes.

\subsection{Statistical Analysis}

We used univariate linear regression model to evaluate if the annual trend in general medical use were statistically significant in each category. The basic characteristics of the patients are presented as the number of patients and percent. The frequency and expenses of each service category and prescription category were analyzed. Each visit were defined as inpatient or outpatient treatments, and categorized by the types of medical institutions. Number of cases were further analyzed by different subtypes of insomnia disease codes of F510 and G470. Types of interventions were defined to analyze the frequency and total expenses. Comorbidities of each patient were categorized by the 1st level and the distribution of comorbidities were shown in terms of number of patients and percentages. All prescriptions were categorized by ATC codes. General medical services were presented by the number of patients, number of cases, total expenses, annual expenses, and annual visits per patient per year. The average log change (as growth rate) of each category were investigated. All cost values were converted to USD based on the 2020 average KRW to USD exchange rate and adjusted using the consumer price index for the healthcare and medical sector of the corresponding year. The data were analyzed using SAS software (version 9.4, SAS Institute, Cary, NC, USA). 


\section{Results}

\subsection{Healthcare Costs}

During the period 2010-2016, a total of 426,232 claims were submitted with ICD10 codes F510 or G470 for insomnia as the main diagnosis. Among these, a total of 339,492 claims for 87,470 patients were selected for analysis in this study (Figure 1 ).

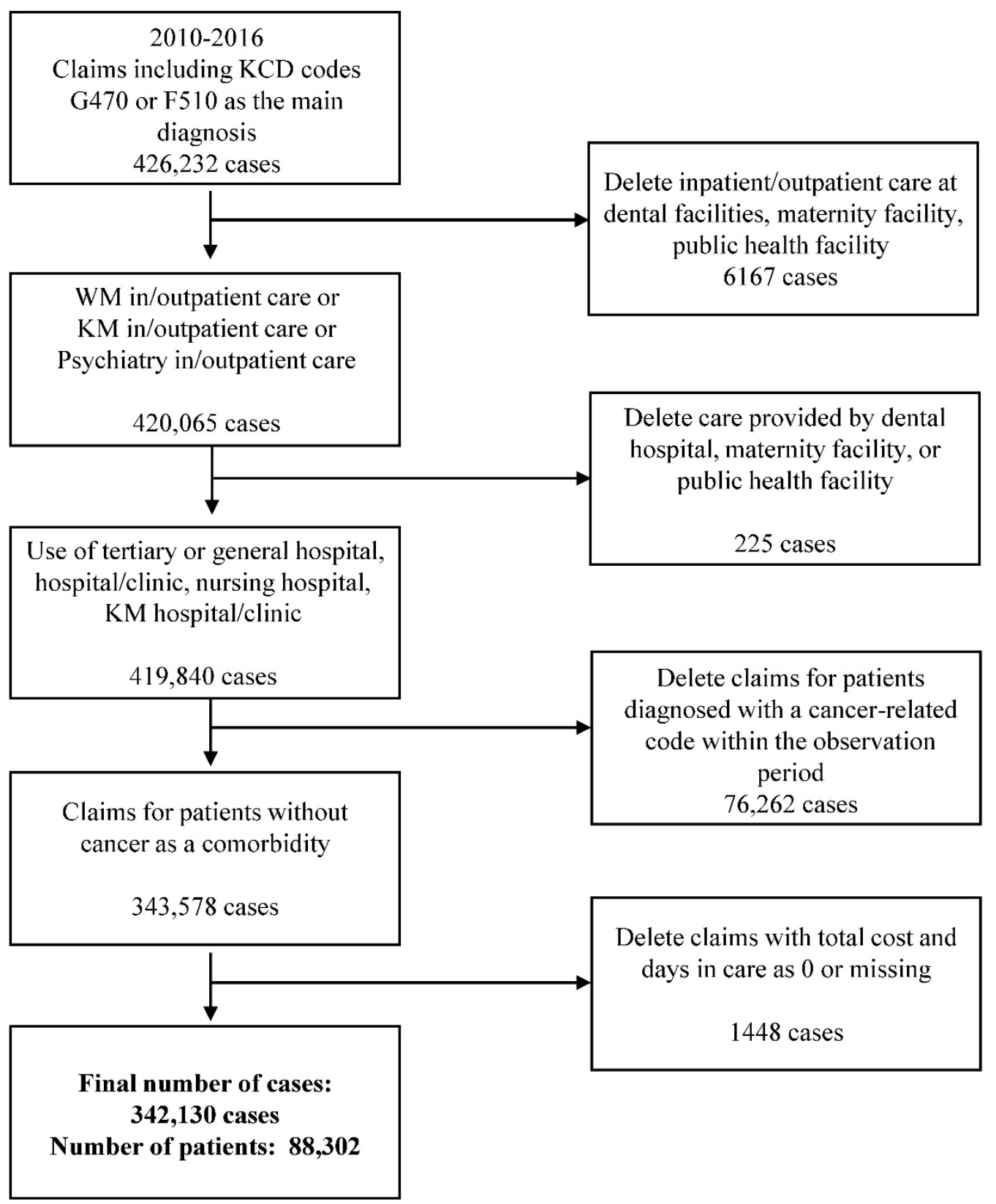

Figure 1. Flowchart of the study sample. $\mathrm{KCD}=$ Korean Standard Classification of Diseases; $\mathrm{WM}=$ Western medicine; $\mathrm{KM}=$ Korean medicine.

As shown in Table 1, a total of 9881 patients sought healthcare for insomnia in 2010, with 1303 visiting a KM facility and 8578 visiting a WM facility; in contrast, a total of 15,362 patients sought healthcare for insomnia in 2016, with 1826 visiting a KM facility and 13,536 visiting a WM facility. This finding indicates that the number of patients seeking medical care for insomnia increased annually over the 7-year study period ( $p$-value $<0.0001)$. While the total number of cases seeking WM care tended to increase over the years, the number of patients seeking KM care did not increase markedly 
(Figure 2, Supplementary Figure S1). The total expense of care in WM consistently increased every year, while that in KM increased only slightly (Supplementary Figure S2). The average per-patient expense of care in KM remained similar over the 7-year period, while that of WM increased every year except for 2011. The average expense per case generally increased consistently over the years for WM, but the annual changes were not consistent for KM, with a higher average expense of care in KM than in WM (Supplementary Figure S3). The number of visits to healthcare facilities remained steady over the study period, and the number of visits to a KM facility was approximately two-fold higher than that to a WM facility (Supplementary Figure S4).

Table 1. General medical service use for patients with insomnia.

\begin{tabular}{|c|c|c|c|c|c|c|c|c|c|}
\hline \multirow{2}{*}{ Category } & \multirow{2}{*}{$\begin{array}{c}\text { Type of } \\
\text { Visit }\end{array}$} & \multicolumn{7}{|c|}{ Year } & \multirow{2}{*}{$p$-Value * } \\
\hline & & 2010 & 2011 & 2012 & 2013 & 2014 & 2015 & 2016 & \\
\hline \multirow{3}{*}{$\begin{array}{l}\text { No. of } \\
\text { patients }\end{array}$} & Total & 9881 & 11,303 & 11,649 & 12,471 & 13,618 & 14,897 & 15,362 & $<0.0001$ \\
\hline & WM & 8578 & 9858 & 10,303 & 11,020 & 11,997 & 13,199 & 13,536 & $<0.0001$ \\
\hline & $\mathrm{KM}$ & 1303 & 1445 & 1346 & 1451 & 1621 & 1698 & 1826 & 0.0016 \\
\hline \multirow{3}{*}{$\begin{array}{l}\text { No. of } \\
\text { cases }\end{array}$} & Total & 35,328 & 40,778 & 43,413 & 47,523 & 53,124 & 58,091 & 61,235 & $<0.0001$ \\
\hline & WM & 29,002 & 33,292 & 36,608 & 39,611 & 44,287 & 49,546 & 51,642 & $<0.0001$ \\
\hline & $\mathrm{KM}$ & 6326 & 7486 & 6805 & 7912 & 8837 & 8545 & 9593 & 0.0022 \\
\hline \multirow{3}{*}{$\begin{array}{c}\text { Total } \\
\text { expense }\end{array}$} & Total & $\$ 529,941$ & $\$ 699,089$ & $\$ 728,091$ & $\$ 890,754$ & $\$ 1,032,866$ & $\$ 1,129,685$ & $\$ 1,143,220$ & $<0.0001$ \\
\hline & WM & $\$ 442,862$ & $\$ 586,277$ & $\$ 626,568$ & $\$ 761,495$ & $\$ 873,214$ & $\$ 979,806$ & $\$ 978,872$ & $<0.0001$ \\
\hline & $\mathrm{KM}$ & $\$ 87,079$ & $\$ 112,812$ & $\$ 101,523$ & $\$ 129,259$ & $\$ 159,652$ & $\$ 149,879$ & $\$ 164,348$ & 0.0019 \\
\hline \multirow{3}{*}{$\begin{array}{c}\text { Per- } \\
\text { patient }\end{array}$} & Total & $\$ 53.63$ & $\$ 61.85$ & $\$ 62.50$ & $\$ 71.43$ & $\$ 75.85$ & $\$ 75.83$ & $\$ 74.42$ & 0.0030 \\
\hline & WM & $\$ 51.63$ & $\$ 59.47$ & $\$ 60.81$ & $\$ 69.10$ & $\$ 72.79$ & $\$ 74.23$ & $\$ 72.32$ & 0.0021 \\
\hline & $\mathrm{KM}$ & $\$ 66.83$ & $\$ 78.07$ & $\$ 75.43$ & $\$ 89.08$ & $\$ 98.49$ & $\$ 88.27$ & $\$ 90.00$ & 0.0269 \\
\hline \multirow{3}{*}{$\begin{array}{l}\text { Per-case } \\
\text { expense }\end{array}$} & Total & $\$ 15.00$ & $\$ 17.14$ & $\$ 16.77$ & $\$ 18.74$ & $\$ 19.44$ & $\$ 19.45$ & $\$ 18.67$ & 0.0140 \\
\hline & WM & $\$ 15.27$ & $\$ 17.61$ & $\$ 17.12$ & $\$ 19.22$ & $\$ 19.72$ & $\$ 19.78$ & $\$ 18.95$ & 0.0190 \\
\hline & $\mathrm{KM}$ & $\$ 13.77$ & $\$ 15.07$ & $\$ 14.92$ & $\$ 16.34$ & $\$ 18.07$ & $\$ 17.54$ & $\$ 17.13$ & 0.0076 \\
\hline \multirow{3}{*}{ Total care } & Total & 141,791 & 188,944 & 210,626 & 230,259 & 267,531 & 297,266 & 286,923 & 0.0002 \\
\hline & WM & 134,732 & 180,738 & 202,962 & 221,534 & 257,775 & 287,662 & 276,514 & 0.0003 \\
\hline & $\mathrm{KM}$ & 7059 & 8206 & 7664 & 8725 & 9756 & 9604 & 10,409 & 0.0010 \\
\hline \multirow{3}{*}{$\begin{array}{c}\text { Av. days } \\
\text { in care } \\
\text { per }\end{array}$} & Total & 24.15 & 29.38 & 29.09 & 29.73 & 32.78 & 33.51 & 30.13 & 0.0478 \\
\hline & WM & 15.88 & 18.51 & 19.84 & 20.25 & 21.66 & 21.93 & 20.58 & 0.0163 \\
\hline & $\mathrm{KM}$ & 8.27 & 10.87 & 9.25 & 9.48 & 11.13 & 11.58 & 9.55 & 0.2982 \\
\hline \multirow{3}{*}{$\begin{array}{l}\text { patient } \\
\text { Total } \\
\text { visits }\end{array}$} & Total & 37,613 & 42,724 & 43,949 & 48,875 & 53,951 & 59,770 & 62,077 & $<0.0001$ \\
\hline & WM & 31,070 & 35,067 & 37,114 & 40,883 & 45,027 & 51,111 & 52,452 & $<0.0001$ \\
\hline & KM & 6543 & 7657 & 6835 & 7992 & 8924 & 8659 & 9625 & 0.0034 \\
\hline \multirow{3}{*}{$\begin{array}{l}\text { Avr visits } \\
\text { per } \\
\text { patient }\end{array}$} & Total & 9.35 & 9.78 & 9.48 & 9.94 & 10.20 & 9.83 & 10.00 & 0.0666 \\
\hline & WM & 3.77 & 3.72 & 3.74 & 3.83 & 3.91 & 4.00 & 4.02 & 0.0024 \\
\hline & $\mathrm{KM}$ & 5.58 & 6.06 & 5.74 & 6.10 & 6.29 & 5.84 & 5.98 & 0.3436 \\
\hline
\end{tabular}

* Univariate linear regression model was used to estimate the annual trend of each category. Abbreviations: KM: Korean Medicine; WM: Western Medicine. 


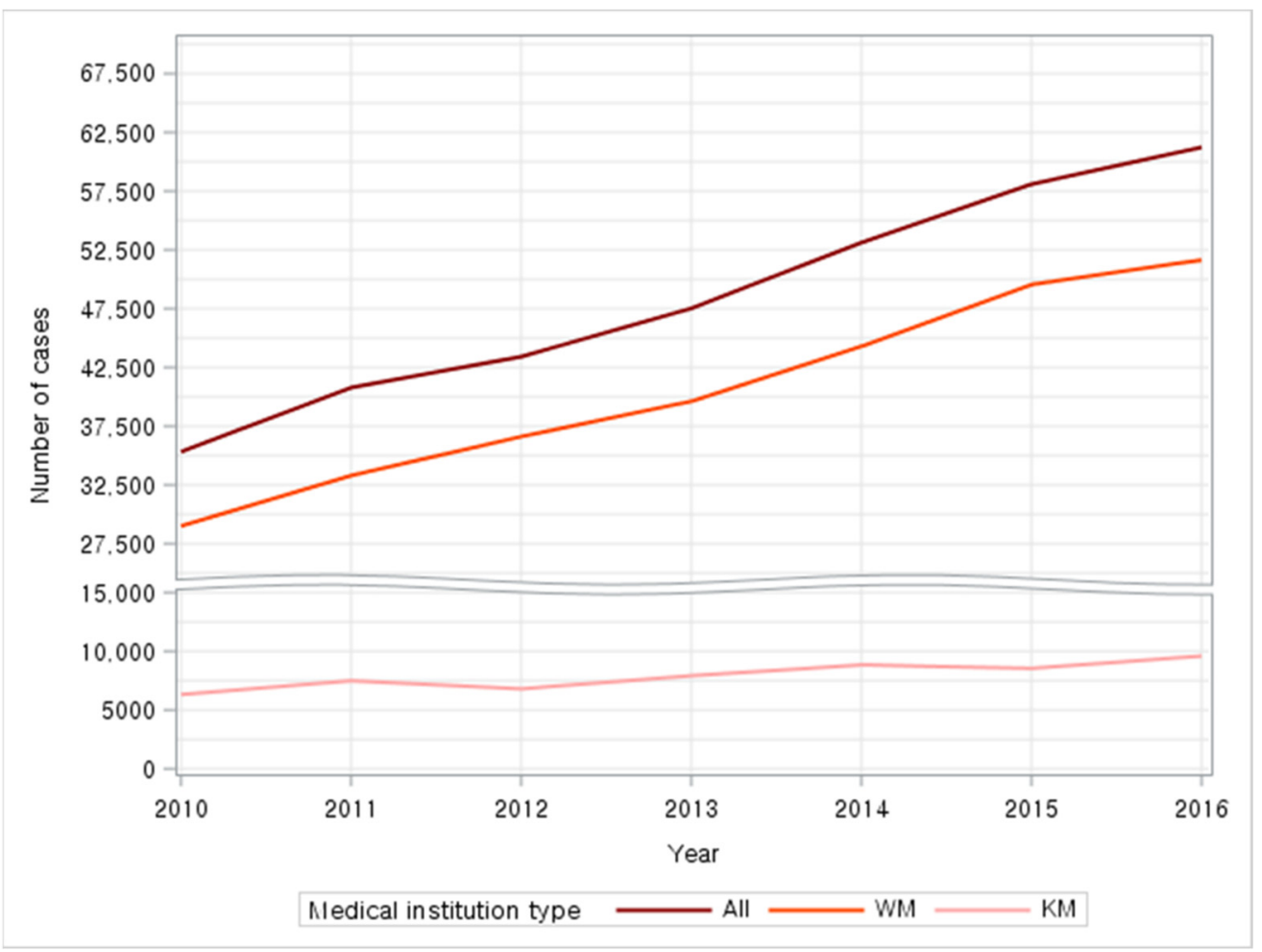

Figure 2. General medical service use for insomnia-number of cases; $\mathrm{WM}=$ Western medicine; $\mathrm{KM}=$ Korean medicine.

\subsection{Baseline Characteristics and Healthcare Utilization}

As shown in Table 2, more female patients $(62.38 \%)$ than male patients $(37.62 \%)$ sought healthcare for insomnia. Most patients were middle aged or older, with the highest number of patients aged 55-64 years (19.60\%), followed by those aged $45-54$ years $(19.40 \%), 65-74$ years $(18.74 \%)$, and $\geq 75$ years $(15.25 \%)$. Most patients only sought WM care ( $\mathrm{n}=76,780,88 \%$ ), while 8979 patients utilized only KM and 1711 utilized both WM and KM. The age distribution was similar between patients utilizing only KM (55-64 years, $21.97 \%$; $45-54$ years, $20.84 \%$; $65-74$ years, $18.90 \%$ ) and those utilizing only WM (55-64 years, $19.20 \%$; $45-54$ years, $19.19 \%$; $65-74$ years, $18.59 \%)$. The main age distribution of patients who utilized both KM and WM was as follows: 55-64 years (25.07\%); 65-74 years (24.49\%); and $45-54$ years $(21.57 \%)$. The percentages of male and female patients were $38.96 \%$ and $61.04 \%$, respectively, among patients only utilizing WM and $27.36 \%$ and $72.64 \%$, respectively, among patients only utilizing $\mathrm{KM}$, indicating that a higher percentage of female patients sought KM care than WM care. The percentages of male and female patients seeking both $\mathrm{KM}$ and WM care were $31.39 \%$ and $68.61 \%$, respectively, also demonstrating that a higher percentage of women sought care. Health insurance was the predominant payer type $(92.95 \%)$, followed by Medicaid (6.93\%). Supplementary Table S1 shows the frequency and percentage of the utilization of outpatient/inpatient care and level of healthcare facility for KM and WM. 
Table 2. Basic characteristics of patients.

\begin{tabular}{|c|c|c|c|c|c|c|c|c|c|}
\hline & & \multicolumn{2}{|c|}{ Total } & \multicolumn{2}{|c|}{ Western Medicine } & \multicolumn{2}{|c|}{ Korean Medicine } & \multicolumn{2}{|c|}{ Both Medicines } \\
\hline & & $\begin{array}{l}\text { No. of } \\
\text { Patients }\end{array}$ & $\%$ & $\begin{array}{l}\text { No. of } \\
\text { Patients }\end{array}$ & $\%$ & $\begin{array}{l}\text { No. of } \\
\text { Patients }\end{array}$ & $\%$ & $\begin{array}{c}\text { No. of } \\
\text { Patients }\end{array}$ & $\%$ \\
\hline \multirow{8}{*}{ Age } & $<15$ years & 359 & 0.41 & 85 & 0.11 & 273 & 3.04 & 1 & 0.06 \\
\hline & $15-24$ & 3108 & 3.55 & 2614 & 3.40 & 468 & 5.21 & 26 & 1.52 \\
\hline & $25-34$ & 8566 & 9.79 & 7647 & 9.96 & 825 & 9.19 & 94 & 5.49 \\
\hline & $35-44$ & 11,596 & 13.26 & 10,301 & 13.42 & 1140 & 12.70 & 155 & 9.06 \\
\hline & $45-54$ & 16,971 & 19.40 & 14,731 & 19.19 & 1871 & 20.84 & 369 & 21.57 \\
\hline & $55-64$ & 17,142 & 19.60 & 14,740 & 19.20 & 1973 & 21.97 & 429 & 25.07 \\
\hline & $65-74$ & 16,392 & 18.74 & 14,276 & 18.59 & 1697 & 18.90 & 419 & 24.49 \\
\hline & $\geq 75$ years & 13,336 & 15.25 & 12,386 & 16.13 & 732 & 8.15 & 218 & 12.74 \\
\hline \multirow{2}{*}{ Sex } & Male & 32,909 & 37.62 & 29,915 & 38.96 & 2457 & 27.36 & 537 & 31.39 \\
\hline & Female & 54,561 & 62.38 & 46,865 & 61.04 & 6522 & 72.64 & 1174 & 68.61 \\
\hline \multirow{3}{*}{ Payer type * } & NHI & 81,302 & 92.95 & 71,080 & 92.58 & 8605 & 95.83 & 1617 & 94.51 \\
\hline & Medicaid & 6064 & 6.93 & 5597 & 7.29 & 374 & 4.17 & 93 & 5.44 \\
\hline & Others & 104 & 0.12 & 103 & 0.13 & - & - & 1 & 0.06 \\
\hline
\end{tabular}

* NHI: National Health Insurance; WM = Western medicine; KM = Korean Medicine.

\subsection{Number of Medical Cases and Medical Costs per Category}

As shown in Table 3, examination was the most commonly practiced category $(531,353$ services, $45.33 \%)$, followed by medication administration (287,899 services, $24.56 \%)$, KM treatment $(147,832$ services, $12.61 \%)$, and psychotherapy $(82,426$ services, $7.03 \%)$. In WM, examination was the most commonly practiced category (466,399 services, $49.31 \%)$, followed by medication administration (276,114 services, $29.19 \%)$ and psychotherapy $(82,426$ services, $8.72 \%)$. In KM, KM treatment was the most commonly practiced category $(147,832$ services, $65.29 \%)$, followed by examination (64,954 services, $28.69 \%)$.

Table 3. Number of medical services and medical expenses per category.

\begin{tabular}{|c|c|c|c|c|c|c|c|c|c|c|c|c|}
\hline \multirow[b]{2}{*}{ Service Category } & \multicolumn{4}{|c|}{ Total } & \multicolumn{4}{|c|}{ Western Medicine } & \multicolumn{4}{|c|}{ Korean Medicine } \\
\hline & $\begin{array}{l}\text { No. of } \\
\text { Services }\end{array}$ & $\%$ & Expenses & $\%$ & $\begin{array}{l}\text { No. of } \\
\text { Services }\end{array}$ & $\%$ & Expenses & $\%$ & $\begin{array}{l}\text { No. of } \\
\text { Services }\end{array}$ & $\%$ & Expenses & $\%$ \\
\hline Examination & 531,353 & 45.33 & $\$ 3,508,362$ & 52.84 & 466,399 & 49.31 & $\$ 3,082,432$ & 54.61 & 64,954 & 28.69 & $\$ 425,930$ & 42.79 \\
\hline $\begin{array}{l}\text { Medication } \\
\text { dedministration }\end{array}$ & 287,899 & 24.56 & $\$ 702,345$ & 10.58 & 276,114 & 29.19 & $\$ 684,515$ & 12.13 & 11,785 & 5.20 & $\$ 17,830$ & 1.79 \\
\hline KM treatment & 147,832 & 12.61 & $\$ 523,799$ & 7.89 & - & - & - & - & 147,832 & 65.29 & $\$ 523,799$ & 52.62 \\
\hline Psychotherapy & 82,426 & 7.03 & $\$ 1,216,909$ & 18.33 & 82,426 & 8.72 & $\$ 1,216,909$ & 21.56 & - & - & - & - \\
\hline Test & 59,587 & 5.08 & $\$ 248,335$ & 3.74 & 59,587 & 6.30 & $\$ 248,335$ & 4.40 & - & - & - & - \\
\hline Injection & 39,101 & 3.34 & $\$ 52,208$ & 0.79 & 39,101 & 4.13 & $\$ 52,208$ & 0.93 & - & - & - & - \\
\hline Treatment/surgery & 15,959 & 1.36 & $\$ 48,490$ & 0.73 & 15,959 & 1.69 & $\$ 48,490$ & 0.86 & - & - & - & - \\
\hline $\begin{array}{l}\text { Diagnostic } \\
\text { radiology }\end{array}$ & 3965 & 0.34 & $\$ 39,915$ & 0.60 & 2715 & 0.29 & $\$ 34,137$ & 0.60 & 1250 & 0.55 & $\$ 5778$ & 0.58 \\
\hline Hospitalization & 2874 & 0.25 & $\$ 280,292$ & 4.22 & 2638 & 0.28 & $\$ 259,955$ & 4.61 & 236 & 0.10 & $\$ 20,337$ & 2.04 \\
\hline Other * & 1205 & 0.10 & $\$ 18,662$ & 0.28 & 843 & 0.09 & $\$ 16,987$ & 0.30 & 362 & 0.16 & $\$ 1675$ & 0.17 \\
\hline
\end{tabular}

* Other: anesthesia, 100 co-insurance; all cost-related results presented in this study were converted to the 2020 level based on healthcare and medical service price index adjusted for healthcare inflation rate and KRW:USD exchange rate (see Supplementary Table S4). KM = Korean medicine.

The category that incurred the greatest total expense over the 7-year period was examination (3,508,362 USD, 52.84\%), followed by psychotherapy (1,216,909 USD, 18.33\%) and medication administration (702,345 USD, 10.58\%). In WM, the categories with the highest total expense were examination (3,082,432 USD, 54.61\%), psychotherapy $(1,216,909$ USD, $21.56 \%)$, and medication administration $(684,515 \mathrm{USD}, 12.13 \%)$, while in KM, the categories with the highest total expense were KM treatment (523,799 USD, 52.62\%) and examination $(425,930$ USD, $42.79 \%)$. 


\subsection{Frequently Prescribed Medications for Insomnia}

As shown in Table 4, the most frequently prescribed drugs were sedatives and hypnotics (208,524 cases), followed by antianxiety drugs (99,000 cases) and antidepressants $(68,145$ cases). The total expense was the highest for sedatives and hypnotics (640,755 USD), followed by antidepressants (376,083 USD) and digestive and metabolism-related drugs (186,367 USD). The per-case expense (6.97 USD) and per-patient expense (38.96 USD) were the highest for antipsychotics.

Table 4. Medications used for patients with insomnia.

\begin{tabular}{cccccc}
\hline Category & $\begin{array}{c}\text { No. of } \\
\text { Prescriptions }\end{array}$ & $\begin{array}{c}\text { Total } \\
\text { Expenses }\end{array}$ & $\begin{array}{c}\text { No. of } \\
\text { Patients }\end{array}$ & $\begin{array}{c}\text { Expenses per } \\
\text { Prescription }\end{array}$ & $\begin{array}{c}\text { Annual } \\
\text { Expenses per } \\
\text { Patient }\end{array}$ \\
\hline $\begin{array}{c}\text { Sedatives and } \\
\text { hypnotics }\end{array}$ & 208,524 & $\$ 585,696$ & 62,189 & $\$ 2.81$ & $\$ 9.42$ \\
Antianxiety drugs & 99,000 & $\$ 146,077$ & 25,732 & $\$ 1.48$ & $\$ 5.68$ \\
Antidepressants & 68,145 & $\$ 345,930$ & 14,530 & $\$ 5.08$ & $\$ 23.81$ \\
Digestive and & 39,418 & $\$ 170,716$ & 15,483 & $\$ 4.33$ & $\$ 11.03$ \\
metabolic drugs & 23,626 & $\$ 53,415$ & 11,236 & $\$ 2.26$ & $\$ 4.75$ \\
Musculoskeletal & 13,740 & $\$ 88,522$ & 2486 & $\$ 6.44$ & $\$ 35.61$ \\
Antipsychotics & 12,101 & $\$ 11,832$ & 2667 & $\$ 0.98$ & $\$ 4.44$ \\
Anticonvulsants & 10,282 & $\$ 39,639$ & 3132 & $\$ 3.86$ & $\$ 12.66$ \\
Cardiovascular & 9497 & $\$ 15,616$ & 5412 & $\$ 1.64$ & $\$ 2.89$ \\
Respiratory & 8429 & $\$ 18,744$ & 4560 & $\$ 2.22$ & $\$ 4.11$ \\
Antihistamines & 14,878 & $\$ 99,959$ & 7300 & $\$ 6.72$ & $\$ 13.69$ \\
Other &
\end{tabular}

All cost-related results presented in this study were converted to the 2020 level based on the healthcare and medical service price index, adjusted for healthcare inflation rate and KRW:USD exchange rate (see Supplementary Table S4).

\subsection{Specific Interventions for Insomnia in WM and KM}

We analyzed frequently performed treatments for insomnia in WM and KM, except for examination, medication administration, and physical therapy (Supplementary Table S2). The total expense for psychotherapy in WM was 1,216,909 USD (82,426 cases). According to treatment category, the total expense was the highest for supportive therapy (786,797.12 USD, 63,478 cases), followed by intensive therapy (323,320.61 USD, 13,870 cases), intensive analytic therapy, and individual treatment. In KM, the total expense was the highest for acupuncture (408,779.61 USD, 103,001 cases), cupping (50,319.11 USD, 11,254 cases), moxibustion (44,772.76 USD, 16,544 cases), and KM psychotherapy (3,758.12 USD, 202 cases). Among KM psychotherapies, gyeongja-pyeongji treatment was most frequently prescribed (1,184.12 USD, 42 cases), followed by oji-sangseung treatment, ijeong-byeongi treatment, and jieon-goron treatment. The per-patient expense for psychotherapy was higher in KM than in WM. Furthermore, psychotherapy incurred the highest annual expense per patient for insomnia patients in both WM (61.35 USD) and KM (43.20 USD) (data not shown).

\subsection{Numbers of Cases of Insomnia with Comorbidities}

As shown in Table 5, we analyzed the comorbidities of insomnia separately for WM and KM. In terms of the ICD-10 code blocks, the top five blocks for comorbidities were $F$ codes (mental and behavioral disorders) $(n=77,064), K$ codes (disease of the digestive system) ( $n=16,858), M$ codes (diseases of the musculoskeletal system and connective tissue) $(n=12,727)$, J codes (diseases of the respiratory system) $(n=11,342)$, and I codes (diseases of the circulatory system) $(n=6737)$ in WM. In KM, the top five blocks were $M$ codes $(n=8925), F$ codes $(n=3591), K$ codes $(n=3288)$, U codes (codes for special purposes) $(\mathrm{n}=2591)$, and $\mathrm{R}$ codes (symptoms, signs, and abnormal clinical and laboratory findings) $(n=2095)$. Mental disorders (F codes), musculoskeletal disorders ( $M$ codes), and digestive diseases (K codes) were included in the top three comorbidity code blocks in both WM and KM. The results were consistent even when WM and KM were analyzed together (F 
codes, $n=80,655 ; M$ codes, $n=21,652 ; K$ codes, $n=20,146)$, and the next most common code blocks were J codes $(n=12,086)$ and $R$ codes $(n=7957)$. U codes for KM diagnosis and diseases were common in KM, while I codes for circulatory diseases were common in WM.

Table 5. Comorbidities of patients with insomnia.

\begin{tabular}{|c|c|c|c|c|c|}
\hline \multicolumn{3}{|c|}{ Western Medicine } & \multicolumn{3}{|c|}{ Korean Medicine } \\
\hline $\begin{array}{c}\text { Diagnostic } \\
\text { Code }\end{array}$ & $\begin{array}{l}\text { No. of } \\
\text { Patients }\end{array}$ & $\%$ & $\begin{array}{l}\text { Diagnostic } \\
\text { Code * }\end{array}$ & $\begin{array}{l}\text { No. of } \\
\text { Patients }\end{array}$ & $\%$ \\
\hline $\mathrm{F}$ & 77,064 & $50.56 \%$ & M & 8925 & $35.67 \%$ \\
\hline $\mathrm{K}$ & 16,858 & $11.06 \%$ & $\mathrm{~F}$ & 3591 & $14.35 \%$ \\
\hline M & 12,727 & $8.35 \%$ & $\mathrm{~K}$ & 3288 & $13.14 \%$ \\
\hline $\mathrm{J}$ & 11,342 & $7.44 \%$ & $\mathrm{U}$ & 2591 & $10.35 \%$ \\
\hline I & 6737 & $4.42 \%$ & $\mathrm{R}$ & 2095 & $8.37 \%$ \\
\hline $\mathrm{R}$ & 5862 & $3.85 \%$ & G & 1150 & $4.60 \%$ \\
\hline G & 5202 & $3.41 \%$ & $S$ & 763 & $3.05 \%$ \\
\hline $\mathrm{E}$ & 4587 & $3.01 \%$ & $\mathrm{~J}$ & 744 & $2.97 \%$ \\
\hline $\mathrm{L}$ & 3229 & $2.12 \%$ & $\mathrm{H}$ & 517 & $2.07 \%$ \\
\hline $\mathrm{N}$ & 3035 & $1.99 \%$ & $\mathrm{~N}$ & 450 & $1.80 \%$ \\
\hline $\mathrm{H}$ & 2610 & $1.71 \%$ & $\mathrm{E}$ & 390 & $1.56 \%$ \\
\hline $\mathrm{B}$ & 1143 & $0.75 \%$ & I & 236 & $0.94 \%$ \\
\hline$S$ & 1107 & $0.73 \%$ & $\mathrm{~L}$ & 202 & $0.81 \%$ \\
\hline A & 493 & $0.32 \%$ & B & 32 & $0.13 \%$ \\
\hline $\mathrm{Z}$ & 242 & $0.16 \%$ & $\mathrm{Z}$ & 24 & $0.10 \%$ \\
\hline $\mathrm{T}$ & 93 & $0.06 \%$ & A & 12 & $0.05 \%$ \\
\hline $\mathrm{Q}$ & 58 & $0.04 \%$ & $\mathrm{~T}$ & 11 & $0.04 \%$ \\
\hline $\mathrm{Y}$ & 16 & $0.01 \%$ & $\mathrm{O}$ & 1 & $0.00 \%$ \\
\hline $\mathrm{O}$ & 1 & $0.00 \%$ & - & - & - \\
\hline
\end{tabular}

${ }^{*}$ A, B: certain infectious and parasitic diseases; E: endocrine, nutritional and metabolic diseases; F: mental, behavioral and neurodevelopmental disorders; G: diseases of the nervous system; H: diseases of the eye, adnexa, ear, mastoid; I: diseases of the circulatory system; J: diseases of the respiratory system; K: diseases of the digestive system; L: diseases of the skin and subcutaneous tissue; M: diseases of the musculoskeletal system and connective tissue; $\mathrm{N}$ : diseases of the genitourinary system; O: pregnancy, childbirth and the puerperium; P: certain conditions originating in the perinatal period; Q: congenital malformations, deformations and chromosomal abnormalities; R: symptoms, signs and abnormal clinical and laboratory findings, not elsewhere classified; $S$, T: injury, poisoning and certain other consequences of external causes; U: codes for special purposes; V, Y: external causes of morbidity; $Z$ : factors influencing health status and contact with health services.

\subsection{Number of Cases According to the ICD-10 Codes F510 and G470}

The number of claims submitted for insomnia care provided at healthcare facilities was 15,509 containing code F510 and 20,195 containing code G470 in 2010 and 26,083 containing code F510 and 36,218 containing code G470 in 2016, showing that claims for both codes increased. Over the 7-year period, code G470 was used more frequently than code F510, and this difference was more evident in KM than in WM. In WM, code F510 was used more frequently than code G470 with the exception of 2010 and 2016, and in KM, code G470 was used more frequently than code F510 (Figure 3). 

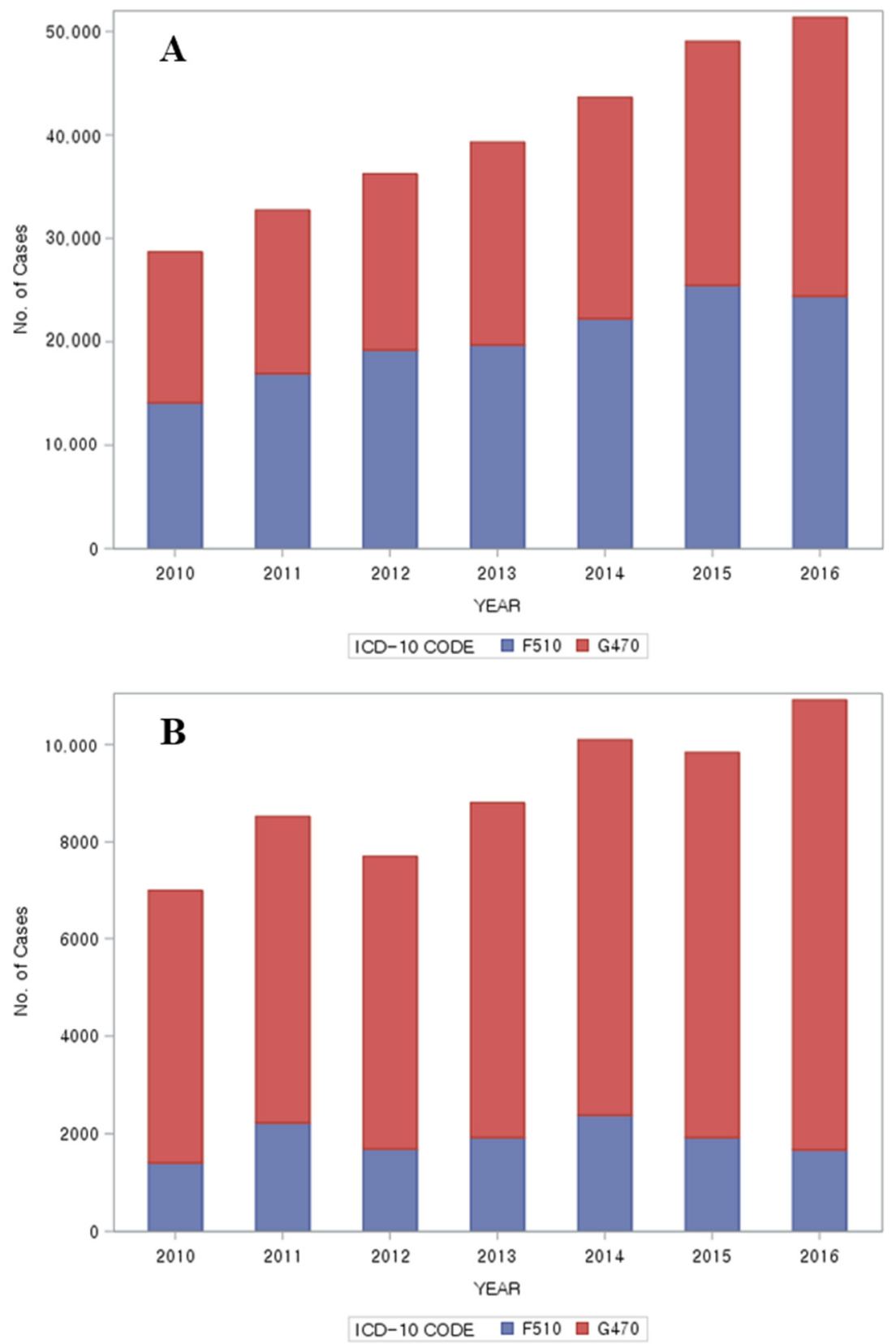

Figure 3. Number of cases per ICD-10 code F510, G470; (A): Western medicine; (B): Korean medicine. ICD-10 = International Classification of Diseases, Tenth Revision.

\section{Discussion}

\subsection{Healthcare Utilization and Medication Usage}

There were approximately 1.7-fold more female patients than male patients among those who sought healthcare for insomnia, which is consistent with previous findings that insomnia more frequently affects women than men [8]. Most patients who sought healthcare for insomnia were in the 55-64 years, $45-54$ years, $65-74$ years, or $\geq 75$ years age groups, with $73 \%$ of the patients aged $\geq 45$ years. There was a high percentage of women aged 45-75 years among patients who sought healthcare for insomnia. The age range of patients seeking KM care for insomnia was 35-74 years, which was similar to the age range of patients seeking KM care for other diseases [33].

Among patients who sought healthcare for insomnia, children and adolescents aged $<15$ years accounted for the smallest proportion $(0.41 \%)$. Although sleep disorders are quite common among children and adolescents, with a prevalence of approximately 
27-62\% [34], their healthcare utilization may be the lowest because only approximately $50 \%$ of caregivers consult a physician for their children's sleep disorders [35]. Compared to other age groups, children and adolescents aged $<15$ years preferred KM care $(3.04 \%)$ to WM care $(0.11 \%)$. This contrasts with the preference for WM care $(16.13 \%)$ over KM care $(8.15 \%)$ among adults aged $\geq 75$ years. As children and adolescents aged $<15$ years have distinct characteristics in terms of healthcare utilization, such as being accompanied by their caregivers when seeking healthcare, further research is needed in this group.

Regarding inpatient and outpatient care utilization as determined based on claims data, outpatient care utilization was remarkably higher than inpatient care at $99.82 \%$. Outpatient care utilization at primary health facilities was high in both KM and WM, with $70.77 \%$ utilizing a WM clinic and $15.84 \%$ utilizing a KM clinic. Insomnia is a very common health problem, and sleep problems frequently occur alongside existing psychological and physical problems. Thus, the prevalence can be high (above 50\%) among patients who visit primary care facilities that are easily accessible [36].

Insomnia is often accompanied by other physical and psychological symptoms [37]. Poor sleep quality and shortened sleep duration may exacerbate symptoms of depression and can contribute to chronic pain by aggravating central sensitization [38]. Previous studies reported that $53 \%$ of patients with chronic pain seek healthcare for sleep-related symptoms [39]. Many studies have provided evidence that irritable bowel syndrome, gastro-esophageal reflux disease, and functional dyspepsia are associated with sleep disorders; the likelihood of developing additional sleep dysfunctions and comorbidities such as anxiety and depression increases with increasing severity of dyspepsia [40]. In our analysis of comorbidities of insomnia, mental disorders (F codes), musculoskeletal disorders (M codes), and digestive diseases (K codes) ranked in the top three comorbidities in both WM and KM. In WM, a high percentage of patients suffered from mental health issues. In KM, a high percentage of patients had a musculoskeletal disorder. According to the 2017 survey of KM care utilization, musculoskeletal and connective tissue-related conditions were the most common reasons (61.1\%) for seeking outpatient KM care, followed by digestive conditions (10.9\%) [33]. This result supports previous findings that acupuncture is effective in treating chronic pain associated with musculoskeletal disorders [41].

In a study of patients with insomnia who visited the Sleep Clinic at the National Center for Mental Health in 2018, Soh (2019) reported that these patients had been treated at a different healthcare facility for sleep problems before visiting the Sleep Clinic and that pharmacological treatment (92\%) was used in most cases [42]. In light of our finding that medication administration was the second-highest category following examination, we can infer that pharmacological treatments are frequently used to treat insomnia in WM. The analysis of frequently prescribed drugs revealed that sedatives and hypnotics were most frequently prescribed, followed by antianxiety drugs and digestive and metabolism-related drugs. Such prescription trends seem to be linked to the top-ranked comorbidities in WM, namely other anxiety disorder (F41), depressive episode (F32), and gastritis and duodenitis (K29).

The most commonly used sedatives and hypnotics were zolpidem, triazolam, and flunitrazepam. Triazolam is a benzodiazepine (BZD) that extends sleep duration and shortens sleep latency; however, withdrawal of the drug may trigger a relapse of insomnia, more severe rebound insomnia, and withdrawal symptoms. Furthermore, triazolam has a short half-life and, thus, may cause more intense withdrawal symptoms. Zolpidem is a BZD receptor agonist that has recently become popular owing to its comparable effects to those of BZDs with reduced tolerance and habituation. Despite the fact that it is effective as a short-term treatment ( $\leq 4$ weeks) for early- and mid-stage insomnia, the use of zolpidem requires caution as it is associated with similar adverse events to those of BZDs (e.g., cognitive decline and falls) and may cause neuropsychiatric adverse events (e.g., parasomnias, amnesia, hallucinations) [43-45]. Thus, hypnotics may be associated with an array of adverse events; in addition, the use of hypnotics is associated with high cancer incidence and mortality $[46,47]$. 
There are several challenges in the clinical implementation of CBT-I, the standard non-pharmacological therapy for insomnia, as it is costly and time consuming, and approximately $20 \%$ of patients with insomnia are nonresponsive to treatment, with $39-44 \%$ failing to retain the therapeutic effects after treatment [21]. We could not examine CBT-I in this study because its health insurance coverage did not commence until 2018. Thus, additional studies are required to investigate the trends and cost of CBT-I.

According to a study conducted among KM doctors, the most common reason for visiting a KM facility among insomnia patients was to enhance their sleep quality and reduce the use of hypnotics, and the most frequently performed treatment was acupuncture along with the administration of herbal medicine [48]. Among various KM psychotherapies, our results showed that ijeong-byeongi therapy and oji-sangseung therapy were most frequently performed (86 cases and 31 cases, respectively). Acupuncture, the most widely performed treatment for insomnia in $\mathrm{KM}$, is associated with few adverse events but high efficacy in the nervous and endocrine systems, and it has been substantiated as an effective alternative medicine modality in many clinical trials [49]. Acupuncture is less costly and can be performed more quickly than psychotherapies. Furthermore, while WM drugs target fixed and specific symptoms of insomnia, acupuncture has an added benefit of adjusting acupoints depending on the targeted symptom [26].

Our analysis of the frequency of insomnia codes F510 and G470 revealed that code G470 was more frequently used than code F510 during the study period, and the difference was more evident in KM than in WM. This is consistent with previous findings that KM doctors frequently use code G470 for insomnia [48]. It is possible that they preferred a G code over an F code because of the patients' psychological burden associated with an F code and the fact that most patients with insomnia also have other symptoms. In 2013, there was an attempt to resolve the negative views and social stigmatization of mental disorders by amending the law to change the main diagnosis to "counseling." Bias not only leads to discrimination against people with mental disorders in their daily lives but also contributes to building a stereotype and negative image of mental disorders. Private and public sectors may intentionally or unintentionally limit opportunities for individuals with mental disorders [50]. A 2016 survey on mental disorders reported that the rate of mental health service utilization by the Korean population remained markedly low at $9.6 \%$, compared to $43 \%$ among the American population (2015) [51]. Hence, changing the perception of mental illnesses and improving mental health services for the affected individuals would be a significant step.

Insomnia often presents as a comorbidity of several other diseases; Thus, it is important to administer individualized treatments for patients by accurately identifying patterns of insomnia, such as difficulty with sleep initiation, maintenance or early morning awakening, as well as each patient's living environment and medical history [52]. While sleep hygiene education and CBT are recommended as first-line treatments for insomnia, it is difficult to implement these interventions in Korea owing to the relatively high cost, lack of practitioners with expertise, and current medical fee system. Therefore, the numbers of patients seeking healthcare for insomnia and hypnotic prescriptions will inevitably increase. The higher utilization of WM than KM observed in our study is presumably because of drug prescriptions. Hypnotics should be prescribed with caution not only due to the associated adverse reactions but also owing to the issues of rebound insomnia, withdrawal symptoms, and recurrence that occur when medications are reduced or stopped [52]. Performing electroacupuncture while to taper off sleeping pills was effective in reducing adverse reactions that typically occur with prolonged use beyond four weeks [53]. Pragmatic observational studies are required to identify effective concomitant treatments and alternatives to pharmacological treatment that are clinically confirmed to improve sleep.

\subsection{Strengths and Limitations}

There are several strengths to this study. Firstly, the data used in this study were collected from the entire population of the country and, thus, are nationally representative. 
Secondly, we observed a long-term period of 7 years, from 2010 to 2016, the latest available data for analysis. Thirdly, this is the first study to analyze trends in insomnia care in both KM and WM in Korea. We analyzed the main treatment modalities and their cost, as well as the frequency of prescribed treatments and medications to treat insomnia, in each specialty.

This study had a few limitations. First, among the cases with insomnia as the main diagnosis, we only analyzed those with the code G470 or F510 with reference to the criteria used in previous studies. Hence, patients who were treated for insomnia with other codes as the main diagnosis or sub-diagnosis may have been omitted. However, because insomnia is associated with various symptoms, we included cases in which insomnia was used as a sub-diagnosis because of differences in the severity of the symptoms in our analysis of comorbidities. Second, we could not analyze clinical manifestations of insomnia (e.g., difficulty of sleep initiation or maintenance) because we used claims data. Furthermore, the degree of impact of insomnia on patients' lives was not examined using scales such as the Insomnia Severity Index or Pittsburgh Sleep Quality Index. Additional studies are needed to investigate varying trends in healthcare utilization according to clinical manifestations and severity of insomnia. Third, it is possible that non-covered treatments such as herbal medicine and chuna therapy were omitted. Moreover, we could not compute the frequency and cost of CBT-I in this study because insurance coverage of CBT-I, which is specifically performed at the neuropsychiatry clinics in WM, was not available during the study period. Subsequent studies should also examine non-covered categories. Fourth, the study included repeated cross-sectional data that enable the analysis of follow-up care over a period of 1 year, but the data lacked yearly continuity. Cohort studies are needed for the long-term analysis of follow-up care. Finally, we analyzed sample data but could not perform an in-depth analysis of psychotherapies performed in KM facilities owing to the smaller number of psychotherapies performed relative to that in WM facilities. This is attributable to the smaller number of KM psychiatrists and the narrower scope of sleep disorder-related psychotherapies that can be performed by KM neuropsychiatrists, thus calling for relevant policy measures.

\section{Conclusions}

In this study, we presented the general trends in the treatment of insomnia in Korea, including the types of treatments, cost of care, and comorbidities, by analyzing the HIRANPS data. The number of patients visiting a primary care facility for insomnia increased annually along with the cost of care, implying an increasing importance of diagnosing insomnia in the clinical field. Furthermore, the overall utilization of pharmacological and non-pharmacological interventions is analyzed to reflect recent practices in Korea. Although psychotherapy is recommended for insomnia prior to prescribing drugs such as hypnotics and sedatives, there are several challenges, such as cost and clinical implementation. Thus, we highlight the need to complement psychotherapies with a focus on clinical utilization, to devise criteria to prevent prolonged use of drugs, and to develop measures to alleviate adverse reactions. In addition, KM utilization for treating insomnia is analyzed and discussed, which warrant further studies regarding its clinical effectiveness. The findings of this study will be useful as a foundation for further investigation of standard insomnia treatments and costs of care.

Supplementary Materials: The following are available online at https:/ / www.mdpi.com/article / 10.3390/healthcare10010007/s1, Figure S1: General medical service use for insomnia-Number of patients, Figure S2: General medical service use for insomnia-Total expenses, Figure S3: General medical service use for insomnia-Annual expenses per patient, Figure S4: General medical service use for insomnia-Annual visits per patient, Table S1: Characteristics of healthcare utilization, Table S2: Specific interventions for insomnia of Western and Korean medicine, Table S3: Anatomical Therapeutic Chemical Classification code by insomnia drug category, Table S4: Annual average KRW-USD exchange rate and price level of health expenses. 


\begin{abstract}
Author Contributions: Conceptualization, C.S., Y.-C.L. and Y.-S.L.; methodology, Y.-C.L. and Y.-S.L.; software, Y.-C.L.; validation, C.S. and Y.-S.L.; formal analysis, Y.-C.L.; investigation, C.S.; data curation, Y.-C.L. and Y.-S.L.; writing—original draft preparation, C.S.; writing-review and editing, Y.-S.L., J.-H.L., B.-K.K. and I.-H.H.; supervision, Y.-S.L., B.-K.K. and I.-H.H.; project administration, Y.-S.L.; funding acquisition, B.-K.K. All authors have read and agreed to the published version of the manuscript.
\end{abstract}

Funding: This research was supported by a grant of the Korea Health Technology R\&D Project through the Korea Health Industry Development Institute (KHIDI), funded by the Ministry of Health \& Welfare, Republic of Korea (grant number: HF20C0178).

Institutional Review Board Statement: The study protocol was approved by the public data provision deliberation committee in the HIRA, and the study was conducted according to relevant guidelines and regulations. The study design was reviewed and qualified as an exemption by the Institutional Review Board of Jaseng Hospital of Korean Medicine, Seoul, Korea (2021-02-023). The analysis has adhered to the principles expressed in the Declaration of Helsinki.

Informed Consent Statement: Because the study analyzed publicly available data, no consent was obtained from the patients; all personal information was de-identified by the National Health Insurance Service prior to public release.

Data Availability Statement: Patient Samples can be obtained via website of HIRA by completing the End User Agreement of the Patient Samples. The Patient Samples are provided in a DVD (text file) format, and a fee is charged for the samples. https:/ / opendata.hira.or.kr/home.do (accessed on 10 December 2021).

Conflicts of Interest: The authors declare no conflict of interest. The funders had no role in the design of the study; in the collection, analyses, or interpretation of data; in the writing of the manuscript; or in the decision to publish the results.

\title{
References
}

1. American Psychiatric Association. Diagnostic and Statistical Manual of Mental Disorders (DSM- $\left.5^{\circledR}\right)$; American Psychiatric Pub: Washington DC, USA, 2013.

2. $\quad$ Ellis, J.G.; Perlis, M.L.; Neale, L.F.; Espie, C.A.; Bastien, C.H. The natural history of insomnia: Focus on prevalence and incidence of acute insomnia. J. Psychiatr. Res. 2012, 46, 1278-1285. [CrossRef]

3. Cho, Y.W.; Shin, W.C.; Yun, C.H.; Hong, S.B.; Kim, J.; Earley, C.J. Epidemiology of insomnia in Korean adults: Prevalence and associated factors. J. Clin. Neurol. 2009, 5, 20-23. [CrossRef]

4. Crowley, K. Sleep and sleep disorders in older adults. Neuropsychol. Rev. 2011, 21, 41-53. [CrossRef]

5. Kim, K.W.; Kang, S.-H.; Yoon, I.-Y.; Lee, S.D.; Ju, G.; Han, J.W.; Kim, T.H.; Lee, C.S.; Kim, T. Prevalence and clinical characteristics of insomnia and its subtypes in the Korean elderly. Arch. Gerontol. Geriatr. 2017, 68, 68-75. [CrossRef]

6. Levenson, J.C.; Kay, D.B.; Buysse, D.J. The pathophysiology of insomnia. Chest 2015, 147, 1179-1192. [CrossRef] [PubMed]

7. Patel, D.; Steinberg, J.; Patel, P. Insomnia in the elderly: A review. J. Clin. Sleep Med. 2018, 14, 1017-1024. [CrossRef] [PubMed]

8. Bhaskar, S.; Hemavathy, D.; Prasad, S. Prevalence of chronic insomnia in adult patients and its correlation with medical comorbidities. J. Fam. Med. Prim. Care 2016, 5, 780. [CrossRef] [PubMed]

9. Parthasarathy, S.; Vasquez, M.M.; Halonen, M.; Bootzin, R.; Quan, S.F.; Martinez, F.D.; Guerra, S. Persistent insomnia is associated with mortality risk. Am. J. Med. 2015, 128, 268-275.e2. [CrossRef]

10. Qaseem, A.; Kansagara, D.; Forciea, M.A.; Cooke, M.; Denberg, T.D. Management of chronic insomnia disorder in adults: A clinical practice guideline from the American College of Physicians. Ann. Intern. Med. 2016, 165, 125-133. [CrossRef]

11. Riemann, D.; Baglioni, C.; Bassetti, C.; Bjorvatn, B.; Dolenc Groselj, L.; Ellis, J.G.; Espie, C.A.; Garcia-Borreguero, D.; Gjerstad, M.; Gonçalves, M. European guideline for the diagnosis and treatment of insomnia. J. Sleep Res. 2017, 26, 675-700. [CrossRef] [PubMed]

12. Schutte-Rodin, S.; Broch, L.; Buysse, D.; Dorsey, C.; Sateia, M. Clinical guideline for the evaluation and management of chronic insomnia in adults. J. Clin. Sleep Med. 2008, 4, 487-504. [CrossRef]

13. Riemann, D.; Perlis, M.L. The treatments of chronic insomnia: A review of benzodiazepine receptor agonists and psychological and behavioral therapies. Sleep Med. Rev. 2009, 13, 205-214. [CrossRef] [PubMed]

14. Choi, H.; Youn, S.; Um, Y.H.; Kim, T.W.; Ju, G.; Lee, H.J.; Lee, C.; Lee, S.D.; Bae, K.; Kim, S.J. Korean Clinical Practice Guideline for the Diagnosis and Treatment of Insomnia in Adults. Psychiatry Investig. 2020, 17, 1048. [CrossRef] [PubMed]

15. Morin, C.M.; Bélanger, L.; LeBlanc, M.; Ivers, H.; Savard, J.; Espie, C.A.; Mérette, C.; Baillargeon, L.; Grégoire, J.-P. The natural history of insomnia: A population-based 3-year longitudinal study. Arch. Intern. Med. 2009, 169, 447-453. [CrossRef]

16. Sateia, M.J.; Buysse, D.J.; Krystal, A.D.; Neubauer, D.N.; Heald, J.L. Clinical practice guideline for the pharmacologic treatment of chronic insomnia in adults: An American Academy of Sleep Medicine clinical practice guideline. J. Clin. Sleep Med. 2017, 13, 307-349. [CrossRef] 
17. Collins, P.Y.; Patel, V.; Joestl, S.S.; March, D.; Insel, T.R.; Daar, A.S.; Bordin, I.A.; Costello, E.J.; Durkin, M.; Fairburn, C. Grand challenges in global mental health. Nature 2011, 475, 27-30. [CrossRef] [PubMed]

18. Gustavsson, A.; Svensson, M.; Jacobi, F.; Allgulander, C.; Alonso, J.; Beghi, E.; Dodel, R.; Ekman, M.; Faravelli, C.; Fratiglioni, L. Cost of disorders of the brain in Europe 2010. Eur. Neuropsychopharmacol. 2011, 21, 718-779. [CrossRef]

19. Daley, M.; Morin, C.M.; LeBlanc, M.; Grégoire, J.-P.; Savard, J. The economic burden of insomnia: Direct and indirect costs for individuals with insomnia syndrome, insomnia symptoms, and good sleepers. Sleep 2009, 32, 55-64.

20. Ahn, D.H. Insomnia: Causes and diagnosis. Hanyang Med. Rev. 2013, 33, 203-209. [CrossRef]

21. Lee, J.-E.; Kim, S.-H.; Kim, B.-K.; Lim, J.-H. A Review on Clinical Research Trend in Treatment of Chai-Hu-Shu-Gan-San (Sihosogan-San) for Insomnia. J. Orient. Neuropsychiatry 2020, 31, 25-38.

22. Song, G.; Lim, G.; Lee, Y.; Song, G.; Park, S.-J. A Review of a Clinical Study on Pharmacopuncture for Insomnia in China. J. Orient. Neuropsychiatry 2019, 30, 265-274.

23. Sivertsen, B.; Krokstad, S.; Mykletun, A.; Øverland, S. Insomnia symptoms and use of health care services and medications: The HUNT-2 study. Behav. Sleep Med. 2009, 7, 210-222. [CrossRef]

24. Yin, X.; Gou, M.; Xu, J.; Dong, B.; Yin, P.; Masquelin, F.; Wu, J.; Lao, L.; Xu, S. Efficacy and safety of acupuncture treatment on primary insomnia: A randomized controlled trial. Sleep Med. 2017, 37, 193-200. [CrossRef] [PubMed]

25. Fu, C.; Zhao, N.; Liu, Z.; Yuan, L.-H.; Xie, C.; Yang, W.-J.; Yu, X.-T.; Yu, H.; Chen, Y.-F. Acupuncture improves peri-menopausal insomnia: A randomized controlled trial. Sleep 2017, 40, zsx153. [CrossRef] [PubMed]

26. Lin, Y.-F.; Liu, Z.-D.; Ma, W.; Shen, W.-D. Hazards of insomnia and the effects of acupuncture treatment on insomnia. J. Integr. Med. 2016, 14, 174-186. [CrossRef]

27. La, Y.K.; Choi, Y.H.; Chu, M.K.; Nam, J.M.; Choi, Y.-C.; Kim, W.-J. Gender differences influence over insomnia in Korean population: A cross-sectional study. PLoS ONE 2020, 15, e0227190. [CrossRef]

28. Lee, M.H.; Choi, J.-W.; Lee, J.; Shin, A.; Oh, S.M.; Jung, S.J.; Lee, Y.J. Trends in prescriptions for sedative-hypnotics among Korean adults: A nationwide prescription database study for 2011-2015. Soc. Psychiatry Psychiatr. Epidemiol. 2019, 54, 477-484. [CrossRef]

29. Kim, L.; Kim, J.-A.; Kim, S. A guide for the utilization of health insurance review and assessment service national patient samples. Epidemiol. Health 2014, 36. [CrossRef] [PubMed]

30. Jeong, S.-Y.; Kim, J.-Y.; Cho, M.-U.; Kho, Y.-T. A Comparative Study between Five Minds Mutual Restriction Therapy and Short-Term Dynamic Psychotherapy (STDP). J. Orient. Neuropsychiatry 2016, 27, 57-65. [CrossRef]

31. The Textbook Compilation Committee of Neuropsychiatry of Oriental Medical Schools in Nation; Jipmoondang: Seoul, Korea, 2011.

32. Lee, Y.S.; Ryu, Y.; Jung, W.M.; Kim, J.; Lee, T.; Chae, Y. Understanding Mind-Body Interaction from the Perspective of East Asian Medicine. Evid. Based Complement. Altern. Med. 2017, 2017, 7618419. [CrossRef]

33. National Institute for Korean Medicine Development. Korean Medicine Utilization and Herbal Medicine Consumption Survey-General Public, 2017; National Institute for Korean Medicine Development: Seoul, Korea, 2018.

34. Yoon, J.M.; Lee, H.R.; Lee, K.H. Characteristics of sleep disorders in childhood and adolescence. J. Korean Child Neurol. Soc. 2007, 15, 185-191.

35. Stein, M.A.; Mendelsohn, J.; Obermeyer, W.H.; Amromin, J.; Benca, R. Sleep and behavior problems in school-aged children Pediatrics 2001, 107, e60. [CrossRef]

36. Bjorvatn, B.; Meland, E.; Flo, E.; Mildestvedt, T. High prevalence of insomnia and hypnotic use in patients visiting their general practitioner. Fam. Pract. 2016, 34, 20-24. [CrossRef] [PubMed]

37. Ha, J.W.; Kim, B.K.; Jung, J.H. A Study on the Correlation of the accompanying symptoms, Heart RatVariability and Body Component Analysis in 350 Insomnia Patients. J. Orient. Neuropsychiatry 2012, 23, 47-62. [CrossRef]

38. Generaal, E.; Vogelzangs, N.; Penninx, B.W.; Dekker, J. Insomnia, sleep duration, depressive symptoms, and the onset of chronic multisite musculoskeletal pain. Sleep 2017, 40,1.

39. Tang, N.K.; Wright, K.J.; Salkovskis, P.M. Prevalence and correlates of clinical insomnia co-occurring with chronic back pain. J. Sleep Res. 2007, 16, 85-95. [CrossRef] [PubMed]

40. Lacy, B.E.; Everhart, K.; Crowell, M.D. Functional dyspepsia is associated with sleep disorders. Clin. Gastroenterol. Hepatol. 2011, 9, 410-414. [CrossRef]

41. Vickers, A.J.; Vertosick, E.A.; Lewith, G.; MacPherson, H.; Foster, N.E.; Sherman, K.J.; Irnich, D.; Witt, C.M.; Linde, K.; Collaboration, A.T. Acupuncture for chronic pain: Update of an individual patient data meta-analysis. J. Pain 2018, 19, 455-474. [CrossRef]

42. Soh, M. Survey of Knowledge on Insomnia for Sleep Clinic Clients. Sleep Med. Psychophysiol. 2019, $26,23-32$.

43. Kim, S.J. Recent advances in diagnosis and treatment of insomnia disorder. J. Korean Neuropsychiatr. Assoc. 2020, 59, 2-12. [CrossRef]

44. Gerlach, L.B.; Wiechers, I.R.; Maust, D.T. Prescription benzodiazepine use among older adults: A critical review. Harv. Rev. Psychiatry 2018, 26, 264. [CrossRef]

45. Wong, C.K.; Marshall, N.S.; Grunstein, R.R.; Ho, S.S.; Fois, R.A.; Hibbs, D.E.; Hanrahan, J.R.; Saini, B. Spontaneous adverse event reports associated with zolpidem in the United States 2003-2012. J. Clin. Sleep Med. 2017, 13, 223-234. [CrossRef] [PubMed]

46. Kripke, D.F.; Langer, R.D.; Kline, L.E. Hypnotics' association with mortality or cancer: A matched cohort study. BMJ Open 2012, 2, e000850. [CrossRef]

47. Walker, M. Why We Sleep: Unlocking the Power of Sleep and Dreams; Simon and Schuster: New York, NY, USA, 2017. 
48. Lim, J.-H.; Jeong, J.-H.; Kim, S.-H.; Kim, K.-O.; Lee, S.-Y.; Lee, S.-H.; Kim, B.-K. The pilot survey of the perception on the practice pattern, diagnosis, and treatment on Korean medicine insomnia: Focusing on the difference between Korean medical neuropsychiatry specialists and Korean medical general practitioners. Evid.-Based Complement. Altern. Med. 2018, 2018, 11. [CrossRef] [PubMed]

49. Zhang, M.; Zhao, J.; Li, X.; Chen, X.; Xie, J.; Meng, L.; Gao, X. Effectiveness and safety of acupuncture for insomnia: Protocol for a systematic review. Medicine 2019, 98, 45. [CrossRef] [PubMed]

50. Rüsch, N.; Angermeyer, M.C.; Corrigan, P.W. Mental illness stigma: Concepts, consequences, and initiatives to reduce stigma. Eur. Psychiatry 2005, 20, 529-539. [CrossRef]

51. Hong, J.-P. The Survey of Mental Disorders in Korea, 2016; Samsung Medical Center, Ministry of Health and Welfare of Korea: Seoul, Korea, 2017.

52. Bahk, W.-M.; Kim, C.H. Textbook of Clinical Neuropsychopharmacology; Korean College of Neuropsychopharmacology: Seoul, Korea, 2019; Volume 3.

53. Yeung, W.-F.; Chung, K.-F.; Zhang, Z.-J.; Zhang, S.-P.; Chan, W.-C.; Ng, R.M.-K.; Chan, C.L.-W.; Ho, L.-M.; Yu, B.Y.-M.; Chau, J.C.-S. Electroacupuncture for tapering off long-term benzodiazepine use: A randomized controlled trial. J. Psychiatr. Res. 2019, 109, 59-67. [CrossRef] [PubMed] 